\title{
Sarcopenia and high NLR are associated with the development of hyperprogressive disease after second-line pembrolizumab in patients with non-small-cell lung cancer
}

\author{
Ivan Donev ${ }^{1}$, Mila Petrova ${ }^{1}$, Maria Radanova ${ }^{2}$, Mariana Eneva $^{1}$, Eleonora Dimitrova ${ }^{3}$, \\ Georgi Valchev ${ }^{4}$, Velko Minchev ${ }^{5}$, Margarita Taushanova ${ }^{5}$, Marsella Boneva ${ }^{5}$, Teodora \\ Karanikolova $^{1}$, Radostina Gencheva ${ }^{1}$, Anika Ivanova ${ }^{1}$, Constanta Timcheva ${ }^{1}$, Boian \\ Pavlov$^{1}$, Vera Megdanova ${ }^{6}$, Bozhil Robev ${ }^{7}$, and Nikolay Conev ${ }^{3}$ \\ ${ }^{1}$ MHAT Nadezhda \\ ${ }^{2}$ Medical University Varna Prof Dr Paraskev Stoyanov \\ ${ }^{3}$ UMHAT St Marina \\ ${ }^{4}$ UMHAT St Marina Varna \\ ${ }^{5}$ University Hospital Sofiamed \\ ${ }^{6}$ University Hospital St Giovanna \\ ${ }^{7}$ UMHAT St Ivan Rilski
}

April 27, 2020

\begin{abstract}
The aim of this multicenter retrospective study was to evaluate the incidence of hyperprogressive disease after treatment with pembrolizumab as a second-line treatment in patients $(\mathrm{n}=167)$ with non-small-cell lung cancer (NSCLC) with metastatic disease whose tumors expressed programmed death-ligand-1 in [?]1\% and to search for factors associated with its development. All patients received platinum-containing chemotherapy as a first-line treatment. The neutrophil to lymphocyte ratio (NLR), platelet to lymphocyte ratio (PLR), and their derivations were retrospectively analyzed. The psoas major muscle area (PMMA) was calculated at the L3 position on computed tomography before chemotherapy and immunotherapy. Patients with [?]PMMA[?]10\% were considered to have sarcopenia (low muscle mass). We also performed multinomial logistic regression to estimate the effects of hematological biomarkers and [?]PMMA on the response to immunotherapy. Hyperprogressors (HPs) had significantly higher NLRs, PLRs and [?]PMMA levels than the other patients. Moreover, in multivariate regression analysis, higher levels of [?]PMMA were associated with a decreased likelihood of being a progressor (P) (OR, 0.81; 95\% CI, 0.65-0.99; p=0.047) or a nonprogressor $(\mathrm{NP})(\mathrm{OR}, 0.76 ; 95 \% \mathrm{CI}, 0.62-0.94 ; \mathrm{p}=0.012)$ vs an HP. In multivariate analysis, higher NLRs tended to decrease the likelihood of being a $\mathrm{P}$ vs an HP (OR, 0.66; 95\% CI, 0.42-1.06; $\mathrm{p}=0.09)$ and significantly decrease the likelihood of being an NP vs an HP (OR, 0.44; 95\% CI, 0.28-0.69; $\mathrm{p}<0.0001)$. Our data suggest that a high pre-immunotherapy NLR and the presence of sarcopenia are potential risk factors for the development of hyperprogressive disease.
\end{abstract}

\section{Introduction}

Lung cancer is the leading cause of cancer death worldwide [1], with non-small-cell lung cancer (NSCLC) accounting for approximately $85 \%$ of lung cancers. Recently, immunotherapy has represented a breakthrough in oncology, especially in its promise to treat a broad range of advanced cancer types, including NSCLC [2]. 
Human immune checkpoint inhibitor antibodies inhibit the programmed death (PD-1) receptor or its ligand PD-L1 and thus restore an efficient antitumour T cell response.

Despite advances in the therapeutic landscape of advanced NSCLC without targetable oncogenic driver alterations regarding immunotherapy, the indication spectrum of these new treatments as monotherapy still includes a minority of patients, whereas the vast majority are inevitably candidates for chemotherapy [3, 4]. In the phase II/III KEYNOTE-010 study, pembrolizumab significantly prolonged overall survival (OS) over docetaxel as second-line therapy in advanced NSCLC [5]. Despite these advances in treatment and the increased knowledge of the molecular pathways, there are still challenges in the identification of those patients who are most likely to benefit and those who will not $[6,7]$. Durable responses can be observed in some populations, although the percentage has often been found to be approximately $20 \%[8,9]$.

Overexpression of PD-L1 is an important and widely explored predictive biomarker for the response to anti-PD-1/PD-L1 antibodies [10]. Previous studies have demonstrated that the tumor microenvironment, with its most important players being neutrophils, platelets, macrophages and regulatory $\mathrm{T}$ cells, plays an essential regulatory role in cancer progression, metastasis and outcome [11, 12]. The results from recent studies suggest that a high neutrophil to lymphocyte ratio (NLR) and platelet to lymphocyte ratio (PLR) may predict a poor response to immune checkpoint inhibitors (ICIs) and poor outcome in patients with NSCLC [13-15]. A recent study proposed that the development of sarcopenia (low muscle mass), measured by the change in the psoas major muscle area (PMMA) at the L3 position, is a negative indicator for the ICI response [16]. In addition to poor responses, immunotherapy was also associated with rapid disease progression, i.e., hyperprogressive disease (HPD), in subpopulations of patients [17] with different incidences [18]. Unfortunately, currently, there are no biomarkers that predict the development of this life-threatening condition.

The purpose of this retrospective study was to evaluate the incidence of HPD after treatment with pembrolizumab as a second-line treatment in metastatic NSCLC patients and to search for indicators that are associated with the development of HPD.

\section{Materials and Methods}

\section{Patient selection}

In this retrospective cohort study, we reviewed the cases of 167 patients from five centers in Bulgaria with metastatic NSCLC treated with pembrolizumab after progression upon first-line platinum-based chemotherapy between April 2017 and February 2020. The procedure was approved by the Scientific Research Ethics Committee at the Hospital "Nadezhda" in Sofia. The eligibility criteria were as follows: (1) age [?]18 years old, (2) histologically confirmed diagnosis of NSCLC in the metastatic stage, (3) wild-type epidermal growth factor receptor/anaplastic lymphoma kinase, (4) Eastern Cooperative Oncology Group-Performance status (ECOG-PS) <2, (5) disease progression after receiving one prior platinum-based systemic therapy for metastatic disease with measurable disease lesions, (6) available blood cell count and blood samples, and (7) available computed tomography $(\mathrm{CT})$ scans. Immunotherapy were administered after at least 3 weeks after previous treatment. Patients were excluded if they had brain metastases (since corticosteroid use may compromise therapy), autoimmune disease, symptomatic interstitial lung disease, systemic immunosuppression, or prior treatment with immune-stimulatory antitumor agents, including checkpoint inhibitors. Patients did not show any clinical or computed tomography signs of active infection. Tumor PD-L1 status was assessed. Pembrolizumab was initially administered via $2 \mathrm{mg} / \mathrm{kg}$ intravenous (i.v.) injection over 60 minutes every 3 weeks and later via $200 \mathrm{mg}$ i.v. injection (flat dose) every 3 weeks.

\section{Data collection}

Data collected included demographics, PD-L1 status, metastatic sites, description of first-line treatment, date of progression as determined by radiology reports, and date of death or last follow-up. Peripheral blood 
samples were collected from patients included in the study the day of first-line chemotherapy administration at baseline and the day of first immunotherapy infusion upon progression. Of interest were the following hematological and biochemistry parameters: absolute neutrophil count (ANC), absolute lymphocyte count (ALC) and platelet count (APC), which enable calculation of the NLR (neutrophil to lymphocyte ratio: ANC/ALC) and the PLR (platelet to lymphocyte ratio: APC/ALC). NLR1 and PLR1 were calculated before the first cycle of chemotherapy, and NLR2 and PLR2 were calculated before the first pembrolizumab infusion. $\triangle$ NLR (NLR2-NLR1) and $\triangle$ PLR (PLR2-PLR1) were calculated. An NLR $>5$ was considered high in accordance with earlier reports [19-21]. The median value of NLR2 was 4.8. The median value (174) of the PLR was used to group cases into two categories of low ([?]median) and high (>median) PLRs.

The tumor PD-L1 protein expression was analyzed by immunohistochemistry of tumor cells in archived biopsy samples of tumors, and the cutoff for positivity was $1 \%$. In addition, we subdivided the positive group into expression categories: expression in 50\%, expression in $25-49 \%$, and expression in $1-24 \%$.

\section{Measurement of psoas major muscle area}

The psoas major muscle area was calculated at the L3 position on computed tomography. The PMMA was calculated before chemotherapy and before pembrolizumab infusion. We were able to measure [?]PMMA in only 112 patients of the whole cohort, since the rest were staged only with a CT scan of the thorax and upper abdomen and the area of the patient's psoas major muscle at the L3 position was not available. The PPMA was measured in the region of interest by tracing an outline using the image viewer software "DICOM". The following formula was used: \% change of PMMA $=\left([1-\mathrm{PMMA} \text { before P/PMMA before CT }]^{*} 100\right.$. Patients with a change in PMMA[?]10\% were considered to have sarcopenia [16].

\section{Endpoints}

The tumor response was assessed according to the Response Evaluation Criteria in Solid Tumors (ver. 1.1) (RECIST 1.1), and clinical tumor response was assessed every 3 months or at clinical deterioration. Hyperprogression was defined if at least three of the following existed: 1 . time to treatment failure $<3$ months; 2 . increase [?]50\% in the sum of target lesion major diameters between baseline and first radiological evaluation; 3. appearance of at least two new lesions in an organ already involved between baseline and first radiological evaluation; 4. spread of the disease to a new organ between baseline and first radiological evaluation; and 5. clinical deterioration with a decrease in ECOG PS [?]2 during the first three months of treatment. Pseudoprogression was defined as initial progression followed either by partial response or stable disease lasting at least 6 months. OS was defined as the interval between diagnosis of the disease and death or the date of the last follow-up evaluation.

\section{Statistical design and analysis}

Data were managed and analyzed using SPSS software ver. 23. The demographic characteristics were expressed as frequencies and percentages for categorical variables and as medians and means with standard deviations for quantitative variables. The Mann-Whitney U test, Spearman correlation and $\chi^{2}$ test were used to compare and evaluate the correlations between the biomarkers and the clinicopathological characteristics of the patients, such as age, sex, the NLR, and the PLR. To assess the correlations between test results, rho values were interpreted as follows: $<0.39$, weak correlation; $0.40-0.59$, moderate correlation; 0.60-0.79, strong correlation; and [?]0.80, very strong correlation. The Kruskal-Wallis one-way analysis of variance with was used to compare the levels of hematological biomarkers, $\triangle$ PMMA and response to pembrolizumab at the first CT scan. The Wilcoxon and McNemar tests were used to compare quantitative and categorical biomarker values and their derivations. The diagnostic accuracy of biomarkers was determined by obtaining the largest possible area under the curve (AUC) in receiver operating characteristic curve (ROC) analysis. AUC values [?]0.9 were considered "excellent", [?]0.80 were considered "good", [?]0.7 were considered "fair" and $<0.70$ were considered "poor". Survival curves according to the response on the first CT scan were estimated using the Kaplan-Meier method, and differences were assessed using the log-rank test. We also 
performed multinomial logistic regression to estimate the effects of hematological biomarkers and [?]PMMA on the response to treatment. Two-tailed p-values $<0.05$ were considered significant.

\section{Results}

\section{Baseline characteristics}

This study included 167 patients who received anti-PD1 treatment with pembrolizumab after failure of firstline chemotherapy. The clinical characteristics of the patients and relations with response on the first CT scan are summarized in Table 1 . The mean age was $60.2 \pm 6.8$ years; most of the patients were men $(64 \%)$, and almost all patients exhibited an ECOG PS of 1 (98\%). The lung was the most common metastatic site (73\%), followed by pleural effusion (59\%) and bone (40\%). All patients were eligible for the examination of tumor PD-L1 expression, of which 13 patients (7.8\%) had expression in more than 50\%, 80 patients $(47.9 \%)$ had expression in 25-49\%, and 74 patients (44.3\%) had expression in 1-24\%. Of all the clinicopathological characteristics of the patients, only NLR2, PLR2 and the presence of sarcopenia were significantly related to the response on the first CT scan (Table 1).

\section{Hematological biomarkers and their relation to response on the first CT scan}

On the first CT scan after chemotherapy treatment, 15 (8.9\%) patients showed progressive disease. After treatment with pembrolizumab on the first CT scan evaluation, these 15 patients were subdivided as follows: 8 hyperprogressors (HPs), 1 pseudoprogressor (PP) and 6 nonprogressors (NPs). These 15 patients had significantly higher NLR1 and PLR1 than the patients without progressive disease $(7.49 \pm 2.8$ vs $4.31 \pm 2.45$; $283.3 \pm 96.5$ vs $207 \pm 102.6$, respectively). Twelve of them had an NLR $>5$, and at least 9 ([?]PMMA was not available for 3) of them had [?]PMMA[?]10\%.

On the first CT scan after immunotherapy treatment, 45 (26.9\%) patients showed progressive disease, and at least 25 ([?]PMMA was not available for 7) of them had [?]PMMA[?]10\%. Of them, 16 patients (9.6\%) were classified as HPs, $5(2.9 \%)$ were classified as PPs, and the remaining $24(14 \%)$ were classified as Ps. Patients with pseudoprogression were without any clinical deterioration and received further treatment with immunotherapy for another 8 weeks, when the control CT scan proved a partial response for 3 patients and stable disease for 2 patients; the response lasted for at least 6 months. Of all HPs, 15 (93\%) had an NLR>5. HPs had higher mean values of NLR2, PLR2 and [?]NLR, but not higher [?]PLR values, than Ps or NPs (Table 2). There was no significant difference in hematological parameters between HPs and PPs, Ps and NPs, Ps and PPs, or NPs and PPs, except for NLR2, for which NPs had significantly lower values than PPs (Table 2).

ROC analysis was performed to explore the potential predictive role of these biomarkers, NLR2, PLR2, $\triangle N L R$, and $\triangle P L R$, as noninvasive biomarkers for discrimination between patients with or without HPD (Table 3). At the optimal cutoff values for NLR2, the biomarker could significantly and well distinguish between patients with or without HPD (AUC $=0.85,95 \%$ CI: $0.75-0.95, \mathrm{p}<0.001$ ) with a sensitivity of $87.5 \%$ and a specificity of $68.9 \%$. PLR2 also allowed significant but fair discrimination between patients with and without HPD (AUC $=0.79,95 \%$ CI: 0.66- 0.92, p < 0.001) with a sensitivity of $75.0 \%$ and a specificity of $64.1 \%$ (Figure $1 \mathrm{~A}$ and $\mathrm{B}$ ). $\triangle \mathrm{NLR}$ could also discriminate between patients with and without HPD, but poorly (Table 3). The Wilcoxon test showed that the ALC and APC did not change significantly from chemotherapy. Nevertheless, the ANC significantly differed between the first cycle of chemotherapy and the first pembrolizumab infusion. The McNemar test showed that the proportion of patients with an NLR $>5$ and a high PLR did not change significantly with chemotherapy treatment.

A significantly strong correlation was detected between NLR1 and PLR1 (rho=0.763) and NLR2 and PLR2 $(\mathrm{rho}=0.785)$, and a moderate correlation was detected between $\triangle \mathrm{NLR}$ and $\triangle \mathrm{PLR}(\mathrm{rho}=0.465)$. 


\section{Sarcopenia and its relation to response on the first CT scan}

The number of patients who developed sarcopenia during chemotherapy treatment was 34 (30.3\%). After treatment with pembrolizumab after the first CT scan evaluation, these patients were subdivided as follows: 15 were HPs, 4 were PPs, 7 were Ps, and 8 were NPs. There was a significant relationship between the presence of sarcopenia and the response on the first CT scan (Table 1).

The Kruskal-Wallis one-way analysis of variance showed that there were significant differences in [?]PMMA only between HPs and Ps (16.2 \pm 4.8 vs $8.3 \pm 8.1 ; \mathrm{p}=0.009)$ and NPs and HPs $(5.8 \pm 13.8$ vs $16.2 \pm 4.8 ; \mathrm{p}<0.0001)$. The Mann-Whitney U test showed that patients with sarcopenia had significantly higher NLR2 and PLR2 values than patients without sarcopenia ( $7.9 \pm 3.2$ vs $3.6 \pm 2.3$ and $315.9 \pm 157.9$ vs $168.7 \pm 93.8$, respectively; both $\mathrm{p}<0.0001)$. ROC analysis revealed that at the cutoff value of $\triangle \mathrm{PMMA}[?] 10 \%$ could distinguish between patients with or without HPD with an $\mathrm{AUC}=0.89$ (95\% CI, 0.82-0.96; $\mathrm{p}<0.0001$ ), and with a sensitivity of $93.8 \%$ and specificity of $79.2 \%$ (Figure 1C). After adjustment for age, sex, PD-L1 expression, number of metastatic sites, NLR, PLR and their derivations, higher levels of [?]PMMA were associated with a decreased likelihood of being a $\mathrm{P}$ vs an HP (OR, 0.81; 95\% CI, 0.65-0.99; $\mathrm{p}=0.047)$ and being an NP vs an HP (OR, 0.76; 95\% CI, 0.62-0.94; $\mathrm{p}=0.012$ ).

A significant but weak correlation was detected between [?]PMMA and NLR2 (rho=0.365), [?]PMMA and PLR2 (rho=0.279), and [?]PMMA and age (rho=0.292).

\section{Association between hematological biomarkers and response on the first CT scan}

In univariate analysis, higher levels of NLR2 and PLR2 were associated with a decreased likelihood of being a P vs an HP (OR, 0.67; 95\% CI, 0.53-0.86; p=0.001; OR, 0.993; 95\% CI, 0.98-0.99; p=0.006, respectively). On univariate analysis, higher levels of NLR2, PLR2 and [?]PLR were associated with a decreased likelihood of being an NP vs an HP (OR, 0.61; 95\% CI, 0.48-0.76; p<0.0001; OR, 0.991; 95\% CI, 0.98-0.99; p <0.0001, OR, 0.994; 95\% CI, 0.98-0.99; $\mathrm{p}=0.008$, respectively). After adjustment for age, sex, PD-L1 expression and number of metastatic sites, higher levels of NLR2 were associated with a decreased likelihood of being an NP vs an HP (OR, 0.44; 95\% CI, 0.28-0.69; $\mathrm{p}<0.0001)$ and showed a trend for being associated with a decreased likelihood of being a $\mathrm{P}$ vs an HP (OR, 0.66; 95\% CI, 0.42-1.06; $\mathrm{p}=0.09)$ (Table 4).

\section{Overall survival of HPs, PPs, Ps, NPs and patients with sarcopenia}

HPs at the first CT evaluation had a significantly shorter mean OS (9.83 months; 95\%, CI 8.44-11.22) than PPs (19.18 months; 95\%, CI 14.13-24.22) (log-rank test p=0.001), Ps (17.32 months; 95\%, CI 15.67-18.98) (log-rank test $\mathrm{p}<0.001)$ and NPs $(29.79$ months; 95\%, CI 26.87-32.71) (log-rank test $\mathrm{p}<0.001)$ (Figure 2A). Patients with sarcopenia had a significantly shorter mean OS (13.5 months; 95\%, CI 11.7-15.2) than patients without sarcopenia (31.5 months; 95\%, CI 27.6-35.8) (log-rank test p<0.001) (Figure 2B).

\section{Discussion}

The current study found that the incidence of HPD after treatment with pembrolizumab as a second-line therapy was 9.6\%. Higher NLRs and [?]PMMA before treatment with pembrolizumab were associated with a higher risk for the development of HPD. Our results suggest for the first time that in the population of patients who do not respond early to platinum-based chemotherapy, some patients who are at risk for the development of HPD on immunotherapy exist.

ICIs may promote tumor growth kinetics in certain patients and lead to the development of HPD with an incidence in the range from $4 \%$ to $29 \%$ in different studies $[17,22]$ There is no uniform definition for HPD, even though some authors still doubt its existence because it is an ad hoc observation [23]. The majority of researchers rely on the rate of target lesion growth for defining HPD [17, 24, 25]. Since this underestimates the rate of development of metastasis, we included in our study involvement of new lesions as a part of the 
definition for HPD. In conjunction with others, our results suggest that a dramatic increase in tumor growth induced by ICIs is restricted to a relatively small subpopulation of patients, approximately $10 \%[17,22]$. We could not find any association between HPD and age, sex, PS, PD-L1 status, or number of metastatic sites.

Although how and why HPD occurs are still unclear, our results shed some light on this problem. Our results show that the NLR is an important risk factor for the development of HPD. It is well known that high baseline NLR and PLR values and their derivations are linked significantly with worse OS and PFS in patients with NSCLC treated with ICIs $[6,15]$. Although there is no clear explanation for this phenomenon, neutrophils and platelets may promote tumor progression as well as metastases by exercising a direct effect on tumor cells or by indirectly affecting other components of the tumor microenvironment [26, 27]. This effect is achieved through the secretion and release of various chemokines and cytokines, including transforming growth factor-beta, vascular endothelial growth factor, IL-6, IL-8, matrix metalloproteinases and the formation of neutrophil extracellular traps [27]. Neutrophils are considered the most important inflammatory cell population in the tumors of NSCLC patients and promote metastasis, thus potentially compromising the antitumor immune response [28]. Recent studies reported that blood neutrophils, identified by the NLR, were directly linked with the number of intratumoral neutrophil populations, which may have the potential to compromise the antitumor immune response [29]. Lower counts of lymphocytes usually reflect an impairment of cell-mediated immunity. It has been shown that increased infiltration of lymphocytes in the tumor region is associated with better responsiveness to treatment and prognosis in patients with solid tumors [30]. To further complicate the results, it has been shown that activation of tumor lymphocytes could trigger local inflammation and matrix and metabolism modifications that could lead to tumor escape [31]. Moreover, in murine models, it has been shown that HPD is associated with vast infiltration in the tumor microenvironment of primary myeloid cells (mostly precursors of neutrophils and macrophages), which express high levels of activation and inhibitory receptors [32].

Consistent with others, our research finds a positive relationship between sarcopenia and the NLR [33, 34]. Cancer-associated cachexia is a well-known negative prognostic marker with an incidence of up to $40 \%$ in the cancer population [35]. Although there are differences in the definitions used for cachexia and sarcopenia, they are often indistinguishable in clinical practice, and cachexia and its key feature inflammation could lead to sarcopenia [36]. It was shown that sarcopenia measured via [?]PMMA with a CT scan at the L3 position is much more reliable than body mass index, and it is widely used, with a variety of cutoff values $[16,37,38]$. A recent report showed that patients receiving immunotherapy may be particularly susceptible to cancer-associated cachexia [39]. This may explain at least in part why in some patients with pre-existing sarcopenia, immunotherapy may induce rapid tumor growth; upregulation of stress hormone production together with preexisting systemic immunosuppression and the presence of high inflammatory markers such as NLR accelerate tumor growth and thus ultimately lead to HPD.

Several limitations were identified in our study. First, our study is retrospective and has a relatively small sample size; therefore, there is potential for bias. Moreover, the predictive value of the NLR and sarcopenia was not compared to that of some genetic predictive markers, such as EGFR, MDM2 and DNMT3A. Similarly, tumor mutational burden was not available. Second, in our study, only 112 patients (67\%) were available for evaluation of the [?]PMMA. Finally, due to the vague and unclear definitions of HPD in the literature, our definition for this phenomenon might be criticized.

Despite these limitations, our results suggest for the first time that patients with a high NLR and sarcopenia before immunotherapy are at higher risk for hyperprogression and short overall survival. This may be helpful to clinicians in their choice of treatment, especially for patients who progressed rapidly on platinumbased chemotherapy and with high NLRs and sarcopenia; perhaps a combination of chemotherapy and immunotherapy or new molecules in clinical trials could be used for these patients. Drugs that are capable of transforming neutrophils into a functional state with antitumor activity are needed to improve patient outcomes.

Informed consent: For this type of study, formal consent is not required. 
Funding: None declared.

Conflicts of Interest: The authors declare that they have no conflicts of interest.

\section{References}

1. Torre LA, Siegel RL, Ward EM, Jemal A. Global Cancer Incidence and Mortality Rates and Trends-An Update. Cancer epidemiology, biomarkers \& prevention : a publication of the American Association for Cancer Research, cosponsored by the American Society of Preventive Oncology 2016; 25 :16-27.

2. Nixon NA, Blais N, Ernst S, Kollmannsberger C, Bebb G, Butler M, Smylie M, Verma S. Current landscape of immunotherapy in the treatment of solid tumours, with future opportunities and challenges. Current oncology 2018;25 :e373-e84.

3. Prabhash K. Treatment of advanced nonsmall cell lung cancer: First line, maintenance and second line Indian consensus statement update. South Asian journal of cancer 2019; $8: 1-17$.

4. Wu YL, Planchard D, Lu S, Sun H, Yamamoto N, Kim DW, Tan DSW, Yang JC, Azrif M, Mitsudomi T, Park K, Soo RA, Chang JWC, Alip A, Peters S, Douillard JY. Pan-Asian adapted Clinical Practice Guidelines for the management of patients with metastatic non-small-cell lung cancer: a CSCO-ESMO initiative endorsed by JSMO, KSMO, MOS, SSO and TOS. Annals of oncology : official journal of the European Society for Medical Oncology 2019;30:171-210.

5. Herbst RS, Baas P, Kim DW, Felip E, Perez-Gracia JL, Han JY, Molina J, Kim JH, Arvis CD, Ahn MJ, Majem M, Fidler MJ, de Castro G, Jr., Garrido M, Lubiniecki GM, Shentu Y, Im E, Dolled-Filhart M, Garon EB. Pembrolizumab versus docetaxel for previously treated, PD-L1-positive, advanced non-small-cell lung cancer (KEYNOTE-010): a randomised controlled trial. Lancet 2016;387 :1540-50.

6. Jiang T, Bai Y, Zhou F, Li W, Gao G, Su C, Ren S, Chen X, Zhou C. Clinical value of neutrophilto-lymphocyte ratio in patients with non-small-cell lung cancer treated with PD-1/PD-L1 inhibitors. Lung cancer 2019;130:76-83.

7. Rizvi NA, Hellmann MD, Snyder A, Kvistborg P, Makarov V, Havel JJ, Lee W, Yuan J, Wong P, Ho TS, Miller ML, Rekhtman N, Moreira AL, Ibrahim F, Bruggeman C, Gasmi B, Zappasodi R, Maeda Y, Sander C, Garon EB, Merghoub T, Wolchok JD, Schumacher TN, Chan TA. Cancer immunology. Mutational landscape determines sensitivity to PD-1 blockade in non-small cell lung cancer. Science 2015;348 :124-8.

8. Vokes EE, Ready N, Felip E, Horn L, Burgio MA, Antonia SJ, Aren Frontera O, Gettinger S, Holgado E, Spigel D, Waterhouse D, Domine M, Garassino M, Chow LQM, Blumenschein G, Jr., Barlesi F, Coudert B, Gainor J, Arrieta O, Brahmer J, Butts C, Steins M, Geese WJ, Li A, Healey D, Crino L. Nivolumab versus docetaxel in previously treated advanced non-small-cell lung cancer (CheckMate 017 and CheckMate 057): 3 -year update and outcomes in patients with liver metastases. Annals of oncology : official journal of the European Society for Medical Oncology 2018; 29 :959-65.

9. Reck M, Rodriguez-Abreu D, Robinson AG, Hui R, Csoszi T, Fulop A, Gottfried M, Peled N, Tafreshi A, Cuffe S, O'Brien M, Rao S, Hotta K, Vandormael K, Riccio A, Yang J, Pietanza MC, Brahmer JR. Updated Analysis of KEYNOTE-024: Pembrolizumab Versus Platinum-Based Chemotherapy for Advanced Non-Small-Cell Lung Cancer With PD-L1 Tumor Proportion Score of 50\% or Greater. Journal of clinical oncology : official journal of the American Society of Clinical Oncology 2019; 37 :537-46.

10. Meng X, Huang Z, Teng F, Xing L, Yu J. Predictive biomarkers in PD-1/PD-L1 checkpoint blockade immunotherapy. Cancer treatment reviews 2015; 41 :868-76.

11. Diakos CI, Charles KA, McMillan DC, Clarke SJ. Cancer-related inflammation and treatment effectiveness. The Lancet Oncology 2014; 15 :e493-503.

12. Tao H, Mimura Y, Aoe K, Kobayashi S, Yamamoto H, Matsuda E, Okabe K, Matsumoto T, Sugi K, Ueoka H. Prognostic potential of FOXP3 expression in non-small cell lung cancer cells combined with 
tumor-infiltrating regulatory T cells. Lung cancer 2012; 75 :95-101.

13. Petrova MP, Eneva MI, Arabadjiev JI, Conev NV, Dimitrova EG, Koynov KD, Karanikolova TS, Valev SS, Gencheva RB, Zhbantov GA, Ivanova AI, Sarbianova, II, Timcheva CV, Donev IS. Neutrophil to lymphocyte ratio as a potential predictive marker for treatment with pembrolizumab as a second line treatment in patients with non-small cell lung cancer. Bioscience trends 2020;14 :48-55.

14. Diem S, Schmid S, Krapf M, Flatz L, Born D, Jochum W, Templeton AJ, Fruh M. Neutrophil-toLymphocyte ratio (NLR) and Platelet-to-Lymphocyte ratio (PLR) as prognostic markers in patients with non-small cell lung cancer (NSCLC) treated with nivolumab. Lung cancer 2017; 111 :176-81.

15. Russo A, Franchina T, Ricciardi GRR, Battaglia A, Scimone A, Berenato R, Giordano A, Adamo V. Baseline neutrophilia, derived neutrophil-to-lymphocyte ratio (dNLR), platelet-to-lymphocyte ratio (PLR), and outcome in non small cell lung cancer (NSCLC) treated with Nivolumab or Docetaxel. Journal of cellular physiology 2018; $233: 6337-43$.

16. Nishioka N, Uchino J, Hirai S, Katayama Y, Yoshimura A, Okura N, Tanimura K, Harita S, Imabayashi T, Chihara Y, Tamiya N, Kaneko Y, Yamada T, Takayama K. Association of Sarcopenia with and Efficacy of Anti-PD-1/PD-L1 Therapy in Non-Small-Cell Lung Cancer. Journal of clinical medicine 2019;8 .

17. Ferrara R, Mezquita L, Texier M, Lahmar J, Audigier-Valette C, Tessonnier L, Mazieres J, Zalcman G, Brosseau S, Le Moulec S, Leroy L, Duchemann B, Lefebvre C, Veillon R, Westeel V, Koscielny S, Champiat S, Ferte C, Planchard D, Remon J, Boucher ME, Gazzah A, Adam J, Bria E, Tortora G, Soria JC, Besse B, Caramella C. Hyperprogressive Disease in Patients With Advanced Non-Small Cell Lung Cancer Treated With PD-1/PD-L1 Inhibitors or With Single-Agent Chemotherapy. JAMA oncology 2018;4 :1543-52.

18. Tachihara M, Nishimura Y. Who will suffer from hyperprogressive disease in patients with advanced non-small cell lung cancer treated with PD-1/PD-L1 inhibitors.Journal of thoracic disease 2019; 11 :S1289S91.

19. Park W, Kwon D, Saravia D, Desai A, Vargas F, El Dinali M, Warsch J, Elias R, Chae YK, Kim DW, Warsch S, Ishkanian A, Ikpeazu C, Mudad R, Lopes G, Jahanzeb M. Developing a Predictive Model for Clinical Outcomes of Advanced Non-Small Cell Lung Cancer Patients Treated With Nivolumab. Clinical lung cancer 2018; $19: 280-8$ e4.

20. Bagley SJ, Kothari S, Aggarwal C, Bauml JM, Alley EW, Evans TL, Kosteva JA, Ciunci CA, Gabriel PE, Thompson JC, Stonehouse-Lee S, Sherry VE, Gilbert E, Eaby-Sandy B, Mutale F, DiLullo G, Cohen RB, Vachani A, Langer CJ. Pretreatment neutrophil-to-lymphocyte ratio as a marker of outcomes in nivolumabtreated patients with advanced non-small-cell lung cancer. Lung cancer 2017; 106 :1-7.

21. Cedres S, Torrejon D, Martinez A, Martinez P, Navarro A, Zamora E, Mulet-Margalef N, Felip E. Neutrophil to lymphocyte ratio (NLR) as an indicator of poor prognosis in stage IV non-small cell lung cancer. Clinical \& translational oncology : official publication of the Federation of Spanish Oncology Societies and of the National Cancer Institute of Mexico 2012; $14: 864-9$.

22. Champiat S, Dercle L, Ammari S, Massard C, Hollebecque A, Postel-Vinay S, Chaput N, Eggermont A, Marabelle A, Soria JC, Ferte C. Hyperprogressive Disease Is a New Pattern of Progression in Cancer Patients Treated by Anti-PD-1/PD-L1. Clinical cancer research : an official journal of the American Association for Cancer Research 2017;23:1920-8.

23. Frelaut M, Le Tourneau C, Borcoman E. Hyperprogression under Immunotherapy. International journal of molecular sciences $2019 ; 20$.

24. Saada-Bouzid E, Defaucheux C, Karabajakian A, Coloma VP, Servois V, Paoletti X, Even C, Fayette J, Guigay J, Loirat D, Peyrade F, Alt M, Gal J, Le Tourneau C. Hyperprogression during anti-PD-1/PD-L1 therapy in patients with recurrent and/or metastatic head and neck squamous cell carcinoma. Annals of oncology : official journal of the European Society for Medical Oncology 2017; 28 :1605-11. 
25. Kato S, Goodman A, Walavalkar V, Barkauskas DA, Sharabi A, Kurzrock R. Hyperprogressors after Immunotherapy: Analysis of Genomic Alterations Associated with Accelerated Growth Rate. Clinical cancer research : an official journal of the American Association for Cancer Research 2017;23 :4242-50.

26. Klinger MH, Jelkmann W. Role of blood platelets in infection and inflammation. Journal of interferon \& cytokine research : the official journal of the International Society for Interferon and Cytokine Research $2002 ; 22: 913-22$.

27. Treffers LW, Hiemstra IH, Kuijpers TW, van den Berg TK, Matlung HL. Neutrophils in cancer.Immunological reviews 2016; 273 :312-28.

28. Kargl J, Busch SE, Yang GH, Kim KH, Hanke ML, Metz HE, Hubbard JJ, Lee SM, Madtes DK, McIntosh MW, Houghton AM. Neutrophils dominate the immune cell composition in non-small cell lung cancer. Nature communications $2017 ; 8: 14381$.

29. Dumitru CA, Lang S, Brandau S. Modulation of neutrophil granulocytes in the tumor microenvironment: mechanisms and consequences for tumor progression. Seminars in cancer biology 2013; 23 :141-8.

30. Gooden MJ, de Bock GH, Leffers N, Daemen T, Nijman HW. The prognostic influence of tumourinfiltrating lymphocytes in cancer: a systematic review with meta-analysis. Br J Cancer 2011; 105:93-103.

31. Colotta F, Allavena P, Sica A, Garlanda C, Mantovani A. Cancer-related inflammation, the seventh hallmark of cancer: links to genetic instability. Carcinogenesis 2009; 30 :1073-81.

32. Knorr DA, Ravetch JV. Immunotherapy and Hyperprogression: Unwanted Outcomes, Unclear Mechanism. Clinical cancer research : an official journal of the American Association for Cancer Research 2019; $25: 904-6$.

33. Go SI, Park MJ, Song HN, Kang MH, Park HJ, Jeon KN, Kim SH, Kim MJ, Kang JH, Lee GW. Sarcopenia and inflammation are independent predictors of survival in male patients newly diagnosed with small cell lung cancer. Supportive care in cancer : official journal of the Multinational Association of Supportive Care in Cancer 2016; 24 :2075-84.

34. Feliciano EMC, Kroenke CH, Meyerhardt JA, Prado CM, Bradshaw PT, Kwan ML, Xiao J, Alexeeff S, Corley D, Weltzien E, Castillo AL, Caan BJ. Association of Systemic Inflammation and Sarcopenia With Survival in Nonmetastatic Colorectal Cancer: Results From the C SCANS Study. JAMA oncology 2017;3 :e172319.

35. Vigano A, Bruera E, Jhangri GS, Newman SC, Fields AL, Suarez-Almazor ME. Clinical survival predictors in patients with advanced cancer. Archives of internal medicine 2000; 160 :861-8.

36. Rolland Y, Abellan van Kan G, Gillette-Guyonnet S, Vellas B. Cachexia versus sarcopenia.Current opinion in clinical nutrition and metabolic care 2011;14 :15-21.

37. Pecorelli N, Carrara G, De Cobelli F, Cristel G, Damascelli A, Balzano G, Beretta L, Braga M. Effect of sarcopenia and visceral obesity on mortality and pancreatic fistula following pancreatic cancer surgery. The British journal of surgery 2016; $103: 434-42$.

38. Nakamura R, Inage Y, Tobita R, Yoneyama S, Numata T, Ota K, Yanai H, Endo T, Inadome Y, Sakashita S, Satoh H, Yuzawa K, Terashima T. Sarcopenia in Resected NSCLC: Effect on Postoperative Outcomes. Journal of thoracic oncology : official publication of the International Association for the Study of Lung Cancer 2018; 13 :895-903.

39. Flint TR, Janowitz T, Connell CM, Roberts EW, Denton AE, Coll AP, Jodrell DI, Fearon DT. TumorInduced IL-6 Reprograms Host Metabolism to Suppress Anti-tumor Immunity.Cell metabolism 2016; 24 :672-84.

Table 1. Relationship between baseline clinicopathological characteristics of patients and response on the first computed tomography scan - hyperprogressors (HPs), progressors (Ps), and nonprogressors (NPs). 


\begin{tabular}{|c|c|c|c|c|}
\hline & HPs & Ps & NPs & $\mathrm{p}$ value \\
\hline \multicolumn{5}{|l|}{$\overline{\operatorname{Sex}}$} \\
\hline Male & $8(7.5 \%)$ & $16(15 \%)$ & $83(77.6 \%)$ & \multirow[t]{2}{*}{0.35} \\
\hline Female & $8(14.5 \%)$ & $8(14.5 \%)$ & $39(70.9 \%)$ & \\
\hline ECOG PS & & & & \multirow[t]{3}{*}{0.70} \\
\hline 0 & $0(0 \%)$ & $1(25 \%)$ & $3(75 \%)$ & \\
\hline 1 & $16(10.1 \%)$ & $23(14.6 \%)$ & $119(75.3 \%)$ & \\
\hline Lung metastasis & & & & \multirow{3}{*}{0.97} \\
\hline No & $4(10.8 \%)$ & $5(13.5 \%)$ & $28(77.7 \%)$ & \\
\hline Yes & $12(9.8 \%)$ & $18(14.8 \%)$ & $92(75.4 \%)$ & \\
\hline Liver metastasis & & & & \multirow[t]{3}{*}{0.35} \\
\hline No & $10(8.4 \%)$ & $16(13.4 \%)$ & $93(78.2 \%)$ & \\
\hline Yes & $6(15 \%)$ & $7(17.5 \%)$ & $27(67.5 \%)$ & \\
\hline Pleural effusion & & & & \multirow[t]{3}{*}{0.85} \\
\hline No & $5(8.3 \%)$ & $9(15 \%)$ & $46(76.7 \%)$ & \\
\hline Yes & $11(11.1 \%)$ & $14(14.1 \%)$ & $74(74.7 \%)$ & \\
\hline Bone metastasis & & & & \multirow[t]{3}{*}{0.92} \\
\hline No & $10(10.9 \%)$ & $13(14.1 \%)$ & $69(75 \%)$ & \\
\hline Yes & $6(9 \%)$ & $10(14.9 \%)$ & $51(76.1)$ & \\
\hline Number of metastatic lesions & & & & 0.45 \\
\hline$<2$ & $7(7.5 \%)$ & $14(15.1 \%)$ & $72(77.4 \%)$ & \multirow[t]{2}{*}{$? \gtreqless ?$} \\
\hline 2 & $9(13.8 \%)$ & $9(13.8 \%)$ & $48(72.7 \%)$ & \\
\hline PD-L1 expression & & & & \multirow[t]{4}{*}{0.71} \\
\hline $1-24 \%$ & $8(11.6 \%)$ & $12(17.4 \%)$ & $49(71 \%)$ & \\
\hline $25-49 \%$ & $6(7.5 \%)$ & $10(12.5 \%)$ & $64(80 \%)$ & \\
\hline$>50 \%$ & $2(15.4 \%)$ & $2(15.4 \%)$ & $9(69.2 \%)$ & \\
\hline NLR & & & & \multirow[t]{3}{*}{$<0.0001 ?$ ¿? } \\
\hline 5 & $1(1.2 \%)$ & $10(11.8 \%)$ & $74(87.1 \%)$ & \\
\hline$>5$ & $15(19.5 \%)$ & $14(18.2 \%)$ & $48(62.3 \%)$ & \\
\hline PLR & & & & \multirow[t]{3}{*}{$0.004 ? ¿ ?$} \\
\hline median & $3(3.6 \%)$ & $9(10.8 \%)$ & $71(85.5 \%)$ & \\
\hline$>$ median & $13(16.5 \%)$ & $15(19 \%)$ & $51(64.6 \%)$ & \\
\hline Age & & & & 0.71 \\
\hline$<65$ years & $9(8.5 \%)$ & $16(15.1 \%)$ & $81(76.4 \%)$ & \multirow{2}{*}{$? i ?$} \\
\hline 65 years & $7(12.5 \%)$ & $8(14.3 \%)$ & $41(73.2 \%)$ & \\
\hline Sarcopenia & & & & \multirow[t]{3}{*}{$<0.0001$} \\
\hline No & $1(1.3 \%)$ & $11(14.3 \%)$ & $65(84.4 \%)$ & \\
\hline Yes & $15(50 \%)$ & $7(23.3 \%)$ & $8(26.7 \%)$ & \\
\hline
\end{tabular}

Table 2 . Comparison between neutrophil to lymphocyte ratio (NLR), platelet-lymphocyte ratio (PLR), their derivations and response on the first computed tomography scan- hyperprogressors (HPs), pseudoprogressors (PPs), progressors (Ps), and nonprogressors (NPs). Means with standard deviations are shown. Adjusted p-values were used.

\begin{tabular}{lllllllll}
\hline & NLR2 & $\mathrm{p}$ & PLR2 & $\mathrm{p}$ & {$[?] \mathrm{NLR}$} & $\mathrm{p}$ & {$[?] \mathrm{PLR}$} & $\mathrm{p}$ \\
\hline HPs vs Ps & $9.01 \pm 2.66$ & 0.006 & $368.29 \pm 193.8$ & 0.044 & $1.29 \pm 3.02$ & 0.04 & $65.67 \pm 185.31$ & 0.44 \\
& vs & & vs & vs $0.09 \pm 2.3$ & & vs \\
& $5.31 \pm 3.26$ & & $218.53 \pm 108.01$ & & & $24.15 \pm 99.82$
\end{tabular}




\begin{tabular}{|c|c|c|c|c|c|c|c|}
\hline & NLR2 & $\mathrm{p}$ & PLR2 & [?]NLR & $\mathrm{p}$ & [?]PLR & $\mathrm{p}$ \\
\hline $\begin{array}{l}\text { HPs vs } \\
\text { PPs }\end{array}$ & $\begin{array}{l}9.01 \pm 2.66 \\
\text { vs } \\
8.39 \pm 1.32\end{array}$ & 0.91 & $\begin{array}{l}368.29 \pm 193.80 .72 \\
\text { vs } \\
303.09 \pm 115.69\end{array}$ & $\begin{array}{l}1.29 \pm 3.02 \\
\text { vs } \\
2.28 \pm 1.5\end{array}$ & 0.37 & $\begin{array}{l}65.67 \pm 185.31 \\
\text { vs } \\
17.53 \pm 59.75\end{array}$ & 0.78 \\
\hline HPs vs NPs & $\begin{array}{l}9.01 \pm 2.66 \\
\text { vs } \\
4.35 \pm 3.01\end{array}$ & $<0.0001$ & $\begin{array}{l}368.29 \pm 193.8<0.0001 \\
\text { vs } \\
192.67 \pm 109.34\end{array}$ & $\begin{array}{l}1.29 \pm 3.02 \\
\text { vs } \\
0.45 \pm 2.01\end{array}$ & 0.017 & $\begin{array}{l}65.67 \pm 185.31 \\
\text { vs } \\
-9.99 \pm 85.88\end{array}$ & $<0.000$ \\
\hline Ps vs NPs & $\begin{array}{l}5.31 \pm 3.26 \\
\text { vs } \\
4.35 \pm 3.01\end{array}$ & 0.29 & $\begin{array}{l}218.53 \pm 108.010 .36 \\
\text { vs } \\
192.67 \pm 109.34\end{array}$ & $\begin{array}{l}0.09 \pm 2.3 \text { vs } \\
0.45 \pm 2.01\end{array}$ & 0.28 & $\begin{array}{l}24.15 \pm 99.82 \\
\text { vs } \\
-9.99 \pm 85.88\end{array}$ & 0.36 \\
\hline Ps vs PPs & $\begin{array}{l}5.31 \pm 3.26 \\
\text { vs } \\
8.39 \pm 1.32\end{array}$ & 0.25 & $\begin{array}{l}218.53 \pm 108.010 .97 \\
\text { vs } \\
303.09 \pm 115.69\end{array}$ & $\begin{array}{l}0.09 \pm 2.3 \text { vs } \\
2.28 \pm 1.5\end{array}$ & 0.041 & $\begin{array}{l}24.15 \pm 99.82 \\
\text { vs } \\
17.53 \pm 59.75\end{array}$ & 0.98 \\
\hline NPs vs PPs & $\begin{array}{l}4.35 \pm 3.01 \\
\text { vs } \\
8.39 \pm 1.32\end{array}$ & 0.040 & $\begin{array}{l}192.67 \pm 109.340 .31 \\
\text { vs } \\
303.09 \pm 115.69\end{array}$ & $\begin{array}{l}0.45 \pm 2.01 \\
\text { vs } 2.28 \pm 1.5\end{array}$ & 0.10 & $\begin{array}{l}-9.99 \pm 85.88 \\
\text { vs } \\
17.53 \pm 59.75\end{array}$ & 0.30 \\
\hline
\end{tabular}

Table 3. Receiver operating curve (ROC) curve analysis was performed using the neutrophil to lymphocyte ratio (NLR), platelet-lymphocyte ratio (PLR) and their derivations to differentiate between patients with and without hyperprogressive disease. The diagnostic accuracy of biomarkers was determined by obtaining the largest possible area under the curve (AUC) in ROC analysis.

\begin{tabular}{lllll}
\hline Biomarker & AUC 95\% CI & p value & Sensitivity (\%) & Specificity (\%) \\
\hline NLR2 & $0.85(0.75-0.95)$ & $<0.001$ & 87.5 & 68.9 \\
PLR2 & $0.79(0.66-0.92)$ & $<0.001$ & 75.0 & 64.1 \\
$\Delta$ NLR & $0.68(0.54-0.83)$ & 0.016 & 62.5 & 61.3 \\
$\Delta$ PLR & $0.62(0.44-0.79)$ & 0.13 & 56.3 & 60.7 \\
\hline
\end{tabular}

Table 4. Associations between hematological biomarkers and response to pembrolizumab on the first computed tomography scan- hyperprogressors (HPs), progressors (Ps), and nonprogressors (NPs).

\begin{tabular}{llllllll}
\hline Multinomial outcome & Predictor & Unadjusted & Unadjusted & Unadjusted & Adjusted* & Adjusted* & Adjusted* \\
\hline & & OR & $95 \%$ CI & $\mathrm{p}$ & OR & $95 \%$ CI & $\mathrm{p}$ \\
Ps vs HPs & NLR2 & 0.67 & $0.53-0.86$ & 0.001 & 0.66 & $0.42-1.06$ & 0.09 \\
NPs vs HPs & NLR2 & 0.61 & $0.48-0.76$ & $<0.0001$ & 0.44 & $0.28-0.69$ & $<0.0001$ \\
Ps vs HPs & PLR2 & 0.993 & $0.98-0.99$ & 0.006 & 0.992 & $0.98-1.002$ & 0.12 \\
NPs vs HPs & PLR2 & 0.991 & $0.98-0.99$ & $<0.0001$ & 0.999 & $0.99-1.008$ & 0.82 \\
Ps vs HPs & [?]NLR & 0.74 & $0.54-1.02$ & 0.066 & 1.10 & $0.67-1.79$ & 0.69 \\
NPs vs HPs & {$[?] N L R$} & 0.79 & $0.61-1.02$ & 0.070 & 0.69 & $0.38-1.24$ & 0.22 \\
Ps vs HPs & [?]PLR & 0.997 & $0.99-1.002$ & 0.29 & 1.005 & $0.99-1.015$ & 0.36 \\
NPs vs HPs & [?]PLR & 0.994 & $0.98-0.99$ & 0.008 & 0.994 & $0.98-1.003$ & 0.16 \\
\hline
\end{tabular}

*Adjusted for age, sex, PD-L1 expression and number of metastatic sites

\section{Figure Legends}

Figure 1. Receiver operating curve (ROC) curve analysis using the neutrophil to lymphocyte ratio (NLR), the platelet-lymphocyte ratio (PLR) and [?]PMMA to differentiate between patients with and without hyper- 
progressive disease. The diagnostic accuracy of biomarkers was determined by obtaining the largest possible area under the curve (AUC) in ROC analysis A. NLR2 AUC $=0.85 ;$ B. PLR2 AUC $=0.79 ; \mathbf{C}$. [?]PMMA $\mathrm{AUC}=0.89$.

Figure 2. Kaplan-Meier estimates of overall survival (OS) in hyperprogressors (HPs), pseudoprogressors $(\mathrm{PPs})$, progressors (Ps), nonprogressors (NPs) and patients with sarcopenia. A. HPs had a significantly shorter mean OS (9.83 months; 95\%, CI 8.44-11.22) than PPs (19.18 months; 95\%, CI 14.13-24.22) (log-rank test $\mathrm{p}=0.001)$, Ps (17.32 months; 95\%, CI 15.67-18.98) (log-rank test $\mathrm{p}<0.001)$ and NPs $(29.79$ months; $95 \%$, CI 26.87-32.71) (log-rank test $\mathrm{p}<0.001)$. B. Patients with [?]PMMA[?]10\% had a significantly shorter mean OS (13.5 months; 95\%, CI 11.7-15.2) than patients with [?]PMMA<10\% (31.5 months; 95\%, CI 27.6-35.8) $(\log$-rank test $\mathrm{p}<0.001)$.

\section{Figure 1.}
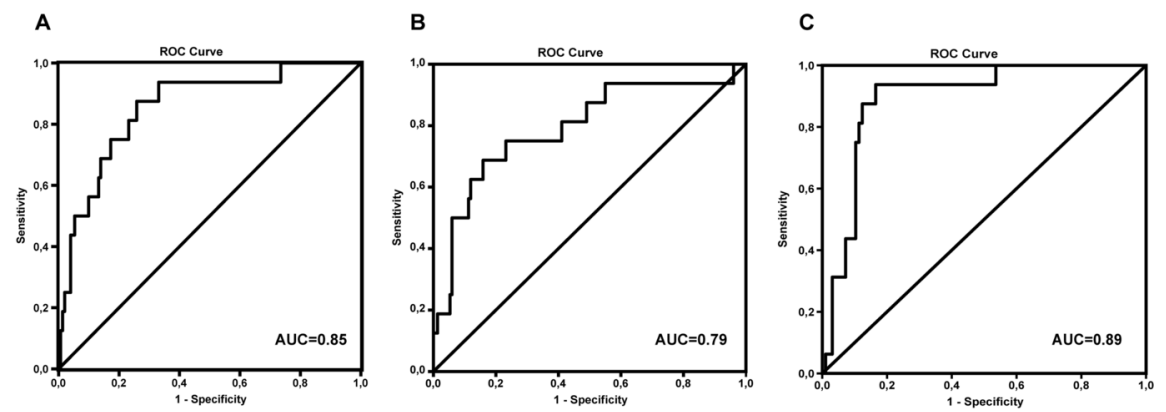

Figure 2.

A

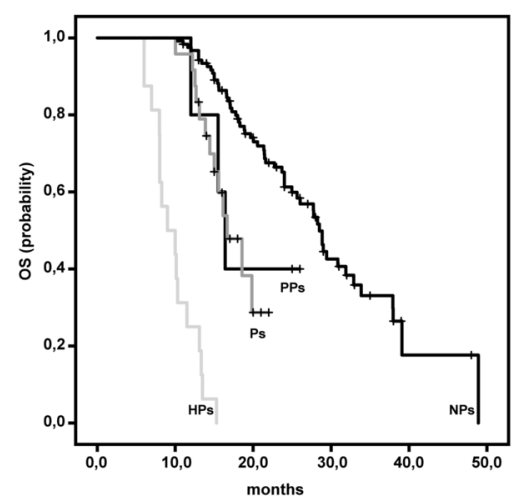

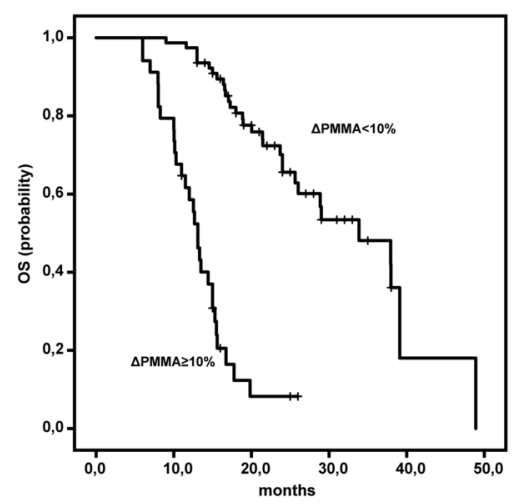

